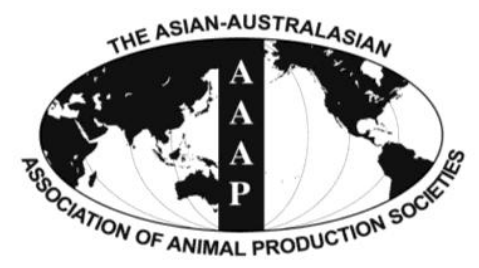

\title{
Comparison of Growth Performance and Whole-body Amino Acid Composition in Red Seabream (Pagrus major) Fed Free or Dipeptide Form of Phenylalanine
}

\author{
Sung-Sam Kim ${ }^{1}$, Samad Rahimnejad ${ }^{1}$, Jin-Woo Song ${ }^{1}$ and Kyeong-Jun Lee ${ }^{1,2, *}$ \\ ${ }^{1}$ Department of Marine Biomedical Science, Jeju National University, Jeju 690-756, Korea
}

\begin{abstract}
This study was conducted to evaluate the efficacy of the dipeptide form of phenylalanine as a new source of amino acid in terms of growth performance and whole-body amino acid composition in comparison to the free form for red seabream (Pagrus major). Fish (1.46 $\pm 0.001 \mathrm{~g}$ ) were fed four isonitrogenous and isocaloric experimental diets containing 0.7 or $1.4 \%$ phenylalanine either in free or dipeptide form. A feeding trial was carried out in three replicates and the fish were fed to apparent satiation for six weeks. At the end of the feeding trial, feed intake of fish was influenced by both phenylalanine form and level and significantly higher values were obtained at an inclusion level of $0.7 \%$ and by the use of dipeptide form. However, the other growth parameters did not significantly differ among treatments. Whole-body amino acid compositions revealed no significant changes in concentrations of both essential and non-essential amino acids regardless of the increase in phenylalanine levels or the use of its different forms. The finding in this study indicates that juvenile red seabream can utilize dipeptide phenylalanine as efficiently as free form without any undesirable effects on growth performance or whole-body amino acid composition. (Key Words: Pagrus major, Phenylalanine, Dipeptide, Amino Acid Requirement)
\end{abstract}

\section{INTRODUCTION}

Fishes at their early life stages (larval and juvenile stages) require higher amino acid levels than those at older stages, because of both a higher growth rate and utilizing amino acids as important source of energy in these stages (Dabrowski, 1986; Rønnestadand and Fyhn, 1993; Rønnestad et al., 1999). Also, the underestimated essential amino acid (EAA) requirement in these stages has been attributed to the suboptimal growth rates when purified diets were used (Dabrowski, 1986; NRC, 1993). AA can be supplied either in the forms of protein-bound, free amino acids or peptides in formulated diets. In mammals it has been proven that absorption of peptides and free AA (FAA) are the major transport routes for protein utilization (Ganapathy et al., 1994; Abidi, 1997). In fish faster absorption of small peptides and FAA in comparison to protein has been shown when they were administered

* Corresponding Author: K-J Lee. Tel: +82-64-754-3423, Fax: +82-64-756-3493, E-mail: kjlee@jejunu.ac.kr

2 Marine and Environmental Research Institute, Jeju National University, Jeju 695-814, Korea.

Submitted Feb. 1, 2012; Accepted May 1, 2012; Revised Jun. 5, 2012 through injection to digestive tract prior to metamorphosis (Rust et al., 1993; Rønnestadet al., 2003). Thus, small peptides and FAA can be regarded as promising dietary AA sources for fishes at early life stages.

Studies on the common carp (Cyprinus carpio) and rainbow trout (Oncorhynchus mykiss) revealed a negative utilization of AA on growth performances when they were fed FAA-based diets in comparison with protein-based diets (Murai, 1982; Murai et al., 1983; Kaushik and Dabrowski, 1983; Dabrowski et al., 2003). It has been suggested that increased deamination or higher total dietary nitrogen excretion through gill and kidney may be partially the reasons for the inferior utilization of FAA-based diets compared to the protein-based diets (Dabrowski et al., 2003). Peptides have different transport systems from FAA. It has been shown that tetra- and larger peptides cannot cover the nitrogen requirements in the absence of pancreatic enzymes or lack of brush border peptidase activity (Grimble, 1994; Daniel, 2004), whereas di- or tripeptides have specific peptide transporters (Doring et al., 1998). These transporters were reported to be expressed in teleost larvae prior to exogenous feeding (Verri et al., 2003).

Phenylalanine is an aromatic AA and its requirement is 
influenced by level of tyrosine in diet. Phenylalanine can be converted to tyrosine, however tyrosine cannot be converted back to phenylalanine. Dietary phenylalanine has a great impact on feed intake, growth performance, immunity and survival of fish in natural environment ( $\mathrm{Li}$ et al., 2008; Pinto et al., 2008). However, only a few studies have been conducted to evaluate the effect of phenylalanine supplementation in diets for aquatic animals. The present study, therefore, was conducted to investigate if juvenile red seabream are able to utilize the dipeptide form of phenylalanine as a new protein source, and also to compare the efficacy of the dipeptide form with the free form in terms of growth performance and whole-body AA composition.

\section{MATERIALS AND METHODS}

\section{Experimental design and diets}

The composition and proximate analysis of a reference diet and experimental diets are provided in Table 1 and 2, respectively. A mixture of synthetic FAA without phenylalanine was prepared according to Dabrowski et al. (2003) and used as the main protein source. All the experimental diets contained $0.4 \%$ phenylalanine from casein. Four semi-purified experimental diets were prepared to contain the equivalent of 0.7 or $1.4 \%$ phenylalanine in free or dipeptide forms. Phenylalanine-Phenylalanine (PhePhe) was used as the dipeptide form and crystalline L-phenylalanine was used as the free form. The experimental diets were kept isonitrogenous and isocaloric using glycine at the expense of phenylalanine. All ingredients were well mixed, pelletized and freeze-dried. The pellets were crushed into desirable particle sizes and stored at $-20^{\circ} \mathrm{C}$ until use. AA concentrations of the experimental diets are provided in Table 3.

\section{Feeding trial}

Juvenile red seabream were transported from a private

Table 1. Formulation of the reference diet

\begin{tabular}{lc}
\hline Ingredients & $\%$ \\
\hline Fish meal & 7.5 \\
Dextrin & 72.5 \\
Vitamin mix. ${ }^{1}$ & 2.0 \\
Mineral mix. $^{2}$ & 2.0 \\
Choline chloride & 1.0 \\
Squid liver oil & 14.0 \\
Taurine & 1.0 \\
\hline${ }^{1}$ Vitamin premix (g/kg of mixture): retinyl acetate, $0.667 ;$ cholecalciferol, \\
0.033; menadione, 0.133; thiamine hydrochloride, $2.667 ;$ riboflavin, \\
2.933; d-pantothenic acid hemicalcium, 9.667; pyridoxine hydrochloride, \\
2.667; cyanocobalamin, $0.007 ;$ niacinamide, 20,000; folic acid, $0.320 ;$ \\
d-biotin, $0.133 ;$ ascorbic acid, 30,000; $\alpha$-tocopherol, 6.667. \\
${ }^{2}$ Mineral mixture was based on the composition of Lee et al. (2003).
\end{tabular}

hatchery to the Marine and Environmental Research Institute of Jeju National University (Jeju Island, South Korea). The fish were acclimated to the experimental facilities and conditions and fed with a microparticulate diet (Love Larva No. 4, Maruha, Shimonoseki, Japan) for one week. Prior to the start of the feeding trial, fish were fed a low-protein diet (reference diet, Table 1) for one week to adapt them to the semi-purified diet and to deplete possible body AA reserves. Fish with an initial weight of $1.46 \pm 0.001$ $\mathrm{g}$ were randomly distributed into 12 tanks of 20 L capacity at a density of 30 fish per tank in a flow through system and supplied with sand filtered seawater at a flow rate of 1.5 $\mathrm{L} / \mathrm{min}$. Water temperature was between 17 and $20^{\circ} \mathrm{C}$ by

Table 2. Composition and proximate analysis of the experimental diets $(\%$ dry matter $)$

\begin{tabular}{|c|c|c|c|c|}
\hline \multirow{2}{*}{ Ingredients } & \multicolumn{4}{|c|}{ Diets (added phenylalanine level \%) } \\
\hline & D-0.7 & D-1.4 & F-0.7 & F-1.4 \\
\hline Casein $^{1}$ & 8.0 & 8.0 & 8.0 & 8.0 \\
\hline FAA $\operatorname{mix}^{2}$ & 38.0 & 38.0 & 38.0 & 38.0 \\
\hline Phe-Phe ${ }^{3}$ & 0.3 & 1.0 & 0.0 & 0.0 \\
\hline Phenylalanine $^{4}$ & 0.0 & 0.0 & 0.3 & 1.0 \\
\hline Glycine $^{5}$ & 0.7 & 0.0 & 0.7 & 0.0 \\
\hline Dextrin $^{6}$ & 32.0 & 32.0 & 32.0 & 32.0 \\
\hline Mineral mix ${ }^{7}$ & 2.0 & 2.0 & 2.0 & 2.0 \\
\hline Vitamin $\operatorname{mix}^{8}$ & 2.0 & 2.0 & 2.0 & 2.0 \\
\hline Squid liver oil $^{9}$ & 15.0 & 15.0 & 15.0 & 15.0 \\
\hline Choline chloride & 1.0 & 1.0 & 1.0 & 1.0 \\
\hline Taurine & 1.0 & 1.0 & 1.0 & 1.0 \\
\hline \multicolumn{5}{|c|}{ Proximate composition } \\
\hline Moisture (\%) & 6.52 & 6.59 & 5.95 & 5.99 \\
\hline Protein $(\%, \mathrm{DM})$ & 47.6 & 46.5 & 47.0 & 46.2 \\
\hline Lipid (\%, DM) & 14.5 & 14.2 & 14.6 & 14.3 \\
\hline Ash $(\%, D M)$ & 1.14 & 1.09 & 1.15 & 1.11 \\
\hline
\end{tabular}

${ }^{1}$ Casein was purchased from USB Co. Ltd., Cleveland, OH, USA.

${ }^{2}$ Free amino acid mixture composition: (g/1,384.11 g dry weight mixture; all L-form amino acids unless otherwise indicated): arginine hydrochloride, 37.8; valine, 37.8 (Fluka, Buchs, Japan); lysine, 45.36; D,L-methionine, 31.5 (WooSung, Daejun, Korea); histidine, 22.05; isoleucine, 28.35; phenylalanine; 56.7; threonine, 25.2; tryptophan, 6.3; proline, 365.4; serine, 365.4; alanine, 362.25 (Sigma Chemicals, St. Louis, MO, USA).

${ }^{3}$ Phe-Phe: Sigma Chemicals, Phenylalanine-Phenylalanine.

${ }^{4}$ Phenylalanine: Sigma Chemicals, L-phenylalanine.

${ }^{5}$ Glycine: Sigma Chemicals, L-Glycine.

${ }^{6}$ Dextrin: Sigma Chemicals, St. Louis, MO, USA.

${ }^{7}$ Mineral premix (g/kg): $\mathrm{MgSO}_{4} \cdot 7 \mathrm{H}_{2} \mathrm{O}, 80.0 ; \mathrm{NaH}_{2} \mathrm{PO}_{4} \cdot 2 \mathrm{H}_{2} \mathrm{O}, 370.0 ; \mathrm{KCl}$, 130.0; Ferric citrate, 40.0; $\mathrm{ZnSO}_{4} 7 \mathrm{H}_{2} \mathrm{O}, 20.0$; Ca-lactate, 356.5; $\mathrm{CuCl}_{2}$, 0.2; $\mathrm{AlCl}_{3} 6 \mathrm{H}_{2} \mathrm{O}, 0.15 ; \mathrm{Na}_{2} \mathrm{Se}_{2} \mathrm{O}_{3}, 0.01 ; \mathrm{MnSO}_{4} \mathrm{H}_{2} \mathrm{O}, 2.0 ; \mathrm{CoCl}_{2} 6 \mathrm{H}_{2} \mathrm{O}$, 1.0 .

${ }^{8}$ Vitamin premix (g/kg): L-ascorbic acid, 121.2; DL- $\alpha$ tocopheryl acetate, 18.8; thiamin hydrochloride, 2.7; riboflavin, 9.1; pyridoxine hydrochloride, 1.8; niacin, 36.4; Ca-D-pantothenate, 12.7; myo-inositol, 181.8; D-biotin, 0.27; folic acid, 0.68; p-aminobezoic acid, 18.2; menadione, 1.8; retinyl acetate, 0.73; cholecalficerol, 0.003; cyanocobalamin, 0.003 .

${ }^{9}$ Squid liver oil was purchased from E-Wha oil Co. Ltd., Busan, Korea. 
Table 3. The total amino acid concentrations of the experimental diets containing different phenylalanine levels and molecular forms (\% dry matter)

\begin{tabular}{lcccc}
\hline Amino acids & D-0.7 & D-1.4 & F-0.7 & F-1.4 \\
\hline EAA & & & & \\
Arginine & 0.65 & 0.64 & 0.64 & 0.63 \\
Histidine & 0.43 & 0.42 & 0.43 & 0.42 \\
Isoleucine & 0.58 & 0.58 & 0.57 & 0.58 \\
Leucine & 1.01 & 1.01 & 0.99 & 1.02 \\
Lysine & 1.28 & 1.27 & 1.19 & 1.20 \\
Methionine & 0.50 & 0.49 & 0.48 & 0.49 \\
Phenylalanine & 0.64 & 1.36 & 0.69 & 1.39 \\
Threonine & 0.44 & 0.44 & 0.44 & 0.44 \\
Valine & 0.83 & 0.83 & 0.84 & 0.84 \\
NEAA & & & & \\
Aspartic acid & 0.26 & 0.27 & 0.26 & 0.28 \\
Glutamic acid & 7.88 & 7.74 & 7.82 & 7.86 \\
Glycine & 8.35 & 7.57 & 8.47 & 7.56 \\
Serine & 0.76 & 0.75 & 0.74 & 0.76 \\
Tyrosine & 0.18 & 0.17 & 0.18 & 0.18 \\
\hline
\end{tabular}

Values are the means of duplicates.

natural fluctuation in seawater temperature. Dissolved oxygen levels were maintained at approximately 7.0 to 8.0 ppm by air stones connected to a central aeration system. Triplicate groups of fish were fed one of the experimental diets to apparent satiation for 6 wks. Fish were initially fed six times a day for the first two weeks and then fed four times a day. The photoperiod was maintained on a 12:12 h light:dark period. Growth was measured every two weeks. Feeding was stopped $18 \mathrm{~h}$ prior to weighing. Experimental protocols followed the guidelines approved by the Animal Care and Use Committee of Jeju National University.

\section{Chemical analysis}

At the end of the feeding trial, all fishes were sampled for whole-body AA analysis. Diets and whole-body samples were freeze-dried and finely ground using a grinder. The proximate composition of the experimental diets was determined by the standard procedures (AOAC, 1995).
Crude protein was determined by Kjeldahl method using an Auto Kjeldahl system (Kejltec System 2300, Sweden). Crude lipid was determined by an ether-extraction method. Moisture was determined by oven drying at $105^{\circ} \mathrm{C}$ for $12 \mathrm{~h}$. Ash was determined by muffle furnace at $550^{\circ} \mathrm{C}$ for $6 \mathrm{~h}$. The AA composition of the experimental diets and wholebody samples was analyzed using an automatic AA analyzer (Biochrom 30, Pharmacia Biotech, Cambridge, England).

\section{Statistical analysis}

All the experimental diets were assigned by a completely randomized design. Data were subjected to twoway analysis of variance (ANOVA) in SPSS version 11.0 (SPSS Inc., Chicago, IL, USA) to assess the effects of phenylalanine form and level on fish growth and wholebody AA composition. Data are presented as means \pm SD. Percentage data were arcsine transformed before statistical analysis.

\section{RESULTS}

The AA composition of the experimental diets is provided in Table 3. The results of analysis confirmed the supplied phenylalanine levels in each test diet. The results of the growth performance are presented in Table 4 . The results showed significant effects of the phenylalanine form and level on feed intake where higher values were obtained in fish fed dipeptide form at the $0.7 \%$ level compared with those fed free form or higher level (Table 6). However, the other growth parameters were not significantly influenced. The survival rate was between 90 to $97 \%$, without significant differences among treatments.

Total AA concentrations of whole-body are provided in Table 5. The obtained results revealed that whole-body AA contents of fish were not affected by higher inclusion level of phenylalanine. Similar whole-body AA concentrations were detected when the fish were fed with either free or dipeptide forms of phenylalanine. Interestingly, the fish group fed $0.7 \%$ dipeptide phenylalanine showed higher essential AA concentrations than the fish group fed the

Table 4. Growth performance of juvenile red seabream fed the experimental diets containing different phenylalanine levels and molecular forms for $6 \mathrm{wks}$

\begin{tabular}{lcccc}
\hline Diets & D- 0.7 & D- 1.4 & F-0.7 & F-1.4 \\
\hline IMBW $(\mathrm{g})^{1}$ & $1.46 \pm 0.06$ & $1.46 \pm 0.04$ & $1.46 \pm 0.06$ & $1.46 \pm 0.05$ \\
FMBW $(\mathrm{g})^{2}$ & $3.00 \pm 0.15$ & $3.00 \pm 0.06$ & $2.99 \pm 0.19$ & $3.02 \pm 0.05$ \\
FI $^{3}$ & $95.0 \pm 0.5$ & $88.5 \pm 2.2$ & $86.8 \pm 1.5$ & $84.9 \pm 1.3$ \\
FCR $^{4}$ & $2.11 \pm 0.17$ & $1.97 \pm 0.16$ & $1.96 \pm 0.23$ & $1.88 \pm 0.12$ \\
PER $^{5}$ & $0.99 \pm 0.08$ & $1.10 \pm 0.09$ & $1.09 \pm 0.14$ & $1.17 \pm 0.07$ \\
Survival (\%) & $90.0 \pm 3.3$ & $93.3 \pm 3.3$ & 96.7 & $91.1 \pm 9.6$ \\
\hline
\end{tabular}

Values are means of triplicate groups; values are presented as mean \pm SD.

${ }^{1} \mathrm{IMBW}=$ Initial mean body weight. ${ }^{2}$ FMBW = Final mean body weight. ${ }^{3}$ Feed intake $(\mathrm{g} / \mathrm{g}$ body weight $)=$ Dry feed fed $(\mathrm{g}) / \mathrm{body}$ weight $(\mathrm{g})$.

${ }^{4}$ Feed conversion ratio $=$ Dry feed fed/wet weight gain. ${ }^{5}$ Protein efficiency ratio $=$ Wet weight gain/total protein fed. 
Table 5. The total (protein-bound+free) amino acid concentrations in the whole-body of juvenile red seabream fed the experimental diets containing different phenylalanine levels and molecular forms (\% dry matter) for $6 \mathrm{wks}$

\begin{tabular}{|c|c|c|c|c|}
\hline Amino acids & D-0.7 & D-1.4 & F-0.7 & F-1.4 \\
\hline \multicolumn{5}{|l|}{$\overline{E A A}$} \\
\hline Arginine & $3.70 \pm 0.40$ & $3.63 \pm 0.72$ & $2.79 \pm 0.66$ & $3.66 \pm 0.87$ \\
\hline Histidine & $1.32 \pm 0.15$ & $1.30 \pm 0.24$ & $0.98 \pm 0.24$ & $1.31 \pm 0.33$ \\
\hline Isoleucine & $2.17 \pm 0.27$ & $2.10 \pm 0.40$ & $1.60 \pm 0.37$ & $2.13 \pm 0.55$ \\
\hline Leucine & $3.97 \pm 0.46$ & $3.85 \pm 0.72$ & $2.96 \pm 0.69$ & $3.94 \pm 0.96$ \\
\hline Lysine & $4.49 \pm 0.63$ & $4.47 \pm 0.82$ & $3.43 \pm 0.71$ & $4.53 \pm 1.03$ \\
\hline Methionine & $1.58 \pm 0.18$ & $1.56 \pm 0.30$ & $1.18 \pm 0.26$ & $1.51 \pm 0.36$ \\
\hline Phenylalanine & $2.25 \pm 0.28$ & $2.21 \pm 0.41$ & $1.71 \pm 0.41$ & $2.25 \pm 0.54$ \\
\hline Threonine & $2.29 \pm 0.31$ & $2.22 \pm 0.47$ & $1.69 \pm 0.41$ & $2.31 \pm 0.58$ \\
\hline Valine & $2.65 \pm 0.29$ & $2.56 \pm 0.46$ & $1.97 \pm 0.42$ & $2.58 \pm 0.62$ \\
\hline \multicolumn{5}{|l|}{$N E A A$} \\
\hline Alanine & $3.55 \pm 0.41$ & $3.60 \pm 0.59$ & $2.70 \pm 0.63$ & $3.58 \pm 0.87$ \\
\hline Aspartic acid & $4.86 \pm 0.56$ & $4.83 \pm 0.78$ & $3.59 \pm 0.82$ & $4.94 \pm 1.04$ \\
\hline Glutamic acid & $7.17 \pm 0.97$ & $7.15 \pm 1.30$ & $5.54 \pm 1.30$ & $7.37 \pm 1.87$ \\
\hline Glycine & $4.60 \pm 0.46$ & $4.68 \pm 0.98$ & $3.56 \pm 0.83$ & $4.65 \pm 1.06$ \\
\hline Proline & $0.92 \pm 1.60$ & $1.78 \pm 1.73$ & $1.57 \pm 1.39$ & $1.10 \pm 1.90$ \\
\hline Serine & $2.22 \pm 0.30$ & $2.14 \pm 0.41$ & $1.62 \pm 0.38$ & $2.22 \pm 0.54$ \\
\hline Tyrosine & $1.79 \pm 0.21$ & $1.75 \pm 0.32$ & $1.34 \pm 0.32$ & $1.74 \pm 0.42$ \\
\hline
\end{tabular}

Values are the means of triplicates.

same level of phenylalanine in free form; however, no significant differences could be detected among treatments.

\section{DISCUSSION}

The optimal dietary phenylalanine requirement has been determined in several fish species including Chinook salmon, Oncorhynchus tshawytscha, (Chance et al., 1964), common carp, Cyprinus carpio (Nose, 1979), channel catfish, Ictalurus punctatus (Robinson et al., 1984), Nile tilapia, Oreochromis niloticus (Santiago and Lovell, 1988), rainbow trout, Oncorhynchus mykiss (Kim et al., 1991) and rohu carp, Labeo rohita (Abidi and Khan, 2007) to be in the range of $0.5 \%$ to $1.7 \%$ in diets. In the present study, therefore, only two levels of phenylalanine at $0.7 \%$ and
$1.4 \%$ were used to compare efficiency of different forms of phenylalanine in either free or dipeptide.

Dabrowski et al. (2003) reported for the first time that a dipeptide based diet can support the growth performance of rainbow trout in the early life stages while a FAA based diet could not. In the present study, red seabream juveniles could consume dipeptide phenylalanine with a similar efficiency to free form. Similarly, Tesser et al. (2005) found that juvenile South American pacu (Piaractus mesopotamicus) can utilize dipeptide arginine without any adverse effects on growth performance in comparison to free form. Also, Kwasek et al. (2010) reported an efficient utilization of dipeptides by koi carp (Cyprinus carpio) without any impairment of growth performance compared to FAA. The first advantage of dietary dipeptides is their

Table 6. Two-way ANOVA of growth parameters of juvenile red seabream fed the experimental diets containing different phenylalanine levels and molecular forms for $6 \mathrm{wks}$

\begin{tabular}{|c|c|c|c|c|c|c|}
\hline Growth parameters & & FBW & FI & FCR & PER & Survival \\
\hline Source & df & ------------- & 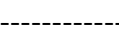 & $F$ value & 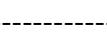 & ----------- \\
\hline AA form $(\mathrm{F})$ & 1 & $\begin{array}{c}0.001 \\
(0.983)\end{array}$ & $\begin{array}{l}45.05 \\
(0.000)\end{array}$ & $\begin{array}{c}1.357 \\
(0.278)\end{array}$ & $\begin{array}{c}2.529 \\
(0.150)\end{array}$ & $\begin{array}{l}1.14 \\
(0.317)\end{array}$ \\
\hline AA level (L) & 1 & $\begin{array}{c}0.025 \\
(0.879)\end{array}$ & $\begin{array}{c}22.777 \\
(0.001)\end{array}$ & $\begin{array}{c}1.206 \\
(0.304)\end{array}$ & $\begin{array}{c}2.529 \\
(0.150)\end{array}$ & $\begin{array}{c}0.079 \\
(0.786)\end{array}$ \\
\hline $\mathrm{F} \times \mathrm{L}$ & 1 & $\begin{array}{c}0.025 \\
(0.879)\end{array}$ & $\begin{array}{c}7.188 \\
(0.028)\end{array}$ & $\begin{array}{c}0.071 \\
(0.797)\end{array}$ & $\begin{array}{c}0.031 \\
(0.864)\end{array}$ & $\begin{array}{c}2.161 \\
(0.180)\end{array}$ \\
\hline Residual & 8 & & & & & \\
\hline Corrected total & 11 & & & & & \\
\hline
\end{tabular}

The data in the parentheses are $\mathrm{p}$ values $(\mathrm{p} \leq 0.05)$. 
attractant properties that can enhance the feed acceptance (Harada, 1989) this property was further confirmed by the significant increase of feed intake in fish fed dipeptide phenylalanine in the present study.

Several studies have attested that whole-body EAA profile can provide a good parameter for the estimation of optimum dietary EAA level in fish (Akiyama, 1987). Kwasek et al. (2010) showed that FAA concentrations (especially EAA) in whole-body can be used as an excellent indicator of the availability of dietary AA sources. In the present study, neither essential nor non-essential AA levels in whole-body were significantly different among the experimental groups. In agreement with our results, Zhang et al. (2006) could not find any significant changes in muscle EAA concentrations of common carp larvae fed FAA or dipeptide based diets. But in contrast, Kwasek et al. (2010) found that the concentrations of threonine, arginine, valine, methionine, isoleucine, leucine, phenylalanine and lysine in the whole-body of koi carp fed FAA based diet were significantly decreased in comparison to those of fish fed dipeptide based diet.

Utilization efficiency of EAA is the most important factor for the evaluation of EAA requirements in fish. The lack of data on the utilization efficiency of the first-limiting EAA is the major weakness in modeling the EAA requirement studies. Available data on the utilization efficiency of the first-limiting EAA in terrestrial animals are still controversial; some researchers observed no effect of dietary EAA level on its utilization efficiency at marginal lysine intake (Susenbeth et al, 1999; Mohn et al., 2000) while others found an increased utilization efficiency of a specific EAA when it was the first-limiting EAA. In fish, lysine utilization efficiency was estimated only in few studies even though many published studies dealt with the response to variable dietary lysine concentrations (Hauler and Carter, 2001a; Wilson, 2003). In Atlantic salmon fed marginal lysine levels, utilization efficiency of lysine was not affected by lysine intake levels and was estimated to be 71 to $78 \%$ (Hauler and Carter, 2001b). Hauler and Carter (2001a) further proposed that marginal lysine intake is utilized with a constant efficiency for weight gain in fish. In rainbow trout, however, a decrease in lysine utilization efficiency with an increase in dietary lysine level has been reported (Rodehutscord et al., 1995). A reduction of lysine utilization efficiency with an increase in intake level is indeed to be expected due to a reduction of lysine absorption rate or its increased catabolization for energy production or both of them.

In this study, interestingly, the fish fed $0.7 \%$ phenylalanine in dipeptide form had higher whole-body AA concentrations than the fish fed $0.7 \%$ of free form while no differences were observed in fish fed $1.4 \%$ level of both free and dipeptide (Table 5). This is very significant result, to our knowledge, because the red seabream fed the marginal level $(0.7 \%)$ of phenylalanine showed differences in their whole-body AA composition accumulating higher AAs from dipeptide than AAs from free form. Therefore, the finding in this study indicates that dipeptide form of AAs can be utilized with higher absorption efficiency compared to free form of AAs in red seabream at the early stages when the AAs were provided with marginal levels. This result suggests that the phenylalanine level of $1.4 \%$ in diet would be higher than its optimum requirement level assuming that its optimum level is likely to be close to $0.7 \%$ in diets for red seabream.

It is unclear whether vertebrates can grow merely on synthetic dipeptide based diet (Dabrowski et al., 2003) or not. Carvalho et al. (1997) reported that the exclusive use of peptide hydrolysate reduced growth rate of koi carp and most of EAA concentrations in whole-body of koi carp decreased when they were provided with FAA or dipeptide based diets. This may indicate that EAA provided in the form of FAA is excreted and/or not used for growth (Murai et al., 1984; Zhang et al., 2006). Absorption of FAA is faster than protein-bound AA and may result in AA imbalances with a low protein utilization (Rønnestad et al., 2000). Moreover, an excess level of di- or tri-peptides can be similarly damaging due to either the saturation of their transport mechanisms (Verri et al., 2003) or their instant hydrolysis to FAAs (Carvalho et al., 2004). However, better absorption of a single peptide compared to a mixture of equal FAA was observed in rainbow trout (Salmo gairdneri R.) (Boge et al., 1981). Partial substitution of protein-bound AA by di- and tripeptides up to $20 \%$ enhanced the growth performances in European sea bass larvae, while higher substitution levels resulted in a reduced performance (Zambonino Infante et al., 1997). Also, it has been suggested that the use of different dipeptides by switching of AA sequence can profoundly affect the absorption characteristics (Daniel, 2004).

Cytosolic and brush border aminopeptidases are considered to be involved in the utilization of dietary peptides (Cahu and Zambonino Infante, 1995; Kurokawa and Suzuki, 1998). The exact mechanism by which the specific peptide transporters in intestinal brush border epithelium are mediated by composition of dipeptides needs to be elucidated in future studies.

In conclusion, both dipeptide and free form of phenylalanine can be used with similar utilization efficiency in red seabream. However, dipeptide form of AA seems to have a higher absorption efficiency than free form of AA when their dietary levels are optimum. An improvement of growth performance with an increment of dietary phenylalanine level to an optimum level was reported while a further inclusion level did not result in better growth performance (Ngamsnae et al., 1999) supporting the 
hypothesis that the optimum phenylalanine requirement would be close to $0.7 \%$ in diets for red seabream juveniles. Protein source is regarded as one of the most important key factors for the estimation of optimum AA requirement for fish (Ngamsnae et al., 1999). According to better utilization efficiency of dipeptide AA in this study, further studies using different levels of dipeptide are required for determination of the optimum phenylalanine requirement. The types of dipeptides, such as Phe-Gly, Phe-Ala and Phe-Pro, could differently affect growth performances of fish. Therefore, further studies are highly recommended that compare different types of dipeptides as the AA sources.

\section{ACKNOWLEDGEMENTS}

This research was supported by the Basic Science Program through the National Research Foundation of Korea (NRF) funded by the Korean government (grant number 2010-0009918).

\section{REFERENCES}

Abidi, S. A. 1997. The oligopeptide transporter (Pept-1) in human intestine: biology and function. Gastroenterology 113:332-340.

Abidi, S. F. and M. A. Khan. 2007. Dietary leucine requirement of fingerling Indian major carp, Labeo rohita (Hamilton). Aquac. Res. 38:478-486.

Akiyama, T. 1987. Studies on the essential amino acids and scoliosis caused by tryptophan deficiency of chum salmon fry. Ph.D. Thesis. University of Kyushu, Fukuoka, Japan.

AOAC (Association of Official Analytical Chemists). 1995. Official methods of analysis. Association of official Analytical Chemists, Arlington, Virginia, USA.

Boge, G., A. Rigal and G. Peres. 1981. Rates of in vivo intestinal absorption of glycine and glycyglycine by rainbow trout (Salmo gairdneri R.). Comp. Biochem. Physiol. 69:455-459.

Cahu, N. and J. L Zambonino Infante. 1995. Effect of the molecular-form of dietary nitrogen supply in sea bass larvaeresponse of pancreatic-enzymes and intestinal peptidases. Fish Physiol. Biochem. 14:209-214.

Carvalho, A. P., A. M. Escaffre, A. Oliva-Teles and P. Bergot. 1997. First feeding of common carp larvae on diets with high levels of protein hydrolysates. Aquac. Int. 5:361-367.

Carvalho, A. P., R. Sa, A. Oliva-Teles and P. Bergot. 2004. Solubility and peptide profile affect the utilization of dietary protein by common carp (Cyprinus carpio) during early larval stages. Aquaculture 234:319-333.

Chance, R. E., E. T. Mertz and J. E. Halver. 1964. Nutrition of salmonid fishes. Isoleucine, leucine, valine and phenylalanine requirements of Chinook salmon and interrelations between isoleucine and leucine for growth. J. Nutr. 83:177-185.

Dabrowski, K. R. 1986. Ontogenetical aspects of nutritional requirements in fish. Comp. Biochem. Physiol. A 85:639-655.

Dabrowski, K., K. Lee and J. Rinchard. 2003. The smallest vertebrate, teleost fish, can utilize synthetic dipeptide-based diets. J. Nutr. 133:4225-4229.

Daniel, H. 2004. Molecular and integrative physiology of intestinal peptide transport. Annu. Rev. Physiol. 66:361-384.

Doring, F., J. Walter, J. Will, M. Focking, M. Boll, S. Amasheh, W. Clauss and H. Daniel. 1998. Delta-aminolevulinic acid transport by intestinal and renal peptide transporters and its physiological and clinical implications. J. Clin. Invest. 101:2761-2767.

Ganapathy, V., M. Brandsch and F. H. Leibach. 1994. Intestinal transport of amino acids and peptides. In: Physiology of gastrointestinal tract (Ed. L. R. Johnson and J. Christensen). Raven Press, New York, USA. pp. 1773-1794.

Grimble, G. 1994. The significance of peptides in clinical nutrition. Annu. Rev. Nutr. 14:419-447.

Harada, K. 1989. Feeding attraction activities of L-dipeptides for abalone, oriental weatherfish and yellowtail. Nippon. Suisan. Gakkaishi. 55:1629-1634.

Hauler, R. C. and C. G. Carter. 2001a. Reevaluation of the quantitative dietary lysine requirements of fish. Rev. Fish. Sci. 9:133-163.

Hauler, R. C. and C. G. Carter. 2001b. Lysine deposition responds linearly to marginal lysine intake in Atlantic salmon (Salmo salar L.) parr. Aquac. Res. 32(Suppl. 1):147-156.

Kaushik, S. J. and K. Dabrowski. 1983. Postprandial metabolic changes in larval and juvenile carp (Cyprinuscarpio). Reprod. Nutr. Dev. 23:223-234.

Kim, K. I., T. B. Kayes and C. H. Amundson. 1991. Purified diet development and re-evaluation of the dietary protein requirement of fingerling rainbow trout (Oncorhynchus mykiss). Aquaculture 96:57-67.

Kurokawa, T. and T. Suzuki. 1998. Development of intestinal brush border aminopeptidase in the larval Japanese flounder Paralichthys olivaceus. Aquaculture. 162:113-124.

Kwasek, K., Y. Zhang and K. Dabrowski. 2010. Utilization of dipeptide/protein based diets in larval and juvenile Koi carppost-prandial free amino acid levels. J. Anim. Physiol. Anim. Nutr. 94:35-43.

Li, P., K. Mai, J. Trushenski and G. Wu. 2008. New developments in fish amino acid nutrition: towards functional and environmentally oriented aquafeeds. Amino Acids DOI: 10.1007/s00726-008-0171-1.

Mohn, S., A. M. Gillis, P. J. Moughan and C. F. Lange. 2000. Influence of dietary lysine and energy intakes on body protein deposition and lysine utilization in the growing pig. J. Anim. Sci. 78:1510-1519.

Murai, T. 1982. Effect of coating amino acids with casein supplmented to gelatin diet on plasma free amino acids of carp. Bull. Jpn. Soc. Sci. Fish. 48:703-710.

Murai, T., Y. Hirasawa, T. Akiyama and T. Nose. 1983. Effects of dietary $\mathrm{pH}$ and electrolyte concentration on the utilization of crystaline amino acids in fingerling carp. Bull. Jpn. Soc. Sci. Fish. 49:1377-1380.

Murai, T., H. Ogata, T. Takeuchi, T. Watanabe and T. Nose. 1984. Composition of free amino acid in excretion of carp fed amino acid diets and casein-gelatin diets. Bull. Jpn. Soc. Sci. Fish. 50:1957-1958.

Ngamsnae, P., S. S. De Silva and R. M. Gunasekera. 1999. Arginine and phenylalanine requirement of juvenile silver perch Bidyanus bidyanus and validation of the use of body amino acid composition for estimating individual amino acid requirements. Aquac. Nutr. 5:173-180. 
Nose, T. 1979. Summary report on the requirements of essential amino acids for carp. In: Finfish Nutrition and Fish feed Technology (Ed. K. Tiews and J. E. Halver). Heenemann GmbH, Berlin, Germany. pp. 145-156

NRC. 1993. National research council nutrient requirements of fish. National Academy Press, Washington, DC, USA.

Pinto, W., L. Figueira, M. T. Dinis and C. Aragaõ. 2008. How does fish metamorphosis affect aromatic amino acid metabolism? Amino Acids doi:10.1007/s00726-008-0045-6.

Robinson, E. H., W. E. Poe and R. P. Wilson. 1984. Effects of feeding diets containing an imbalance of branched-chain amino acids on fingerling channel catfish. Aquaculture 37:5162.

Rodehutscord, M., S. Jacobs, M. Pack and E. Pfeffer. 1995. Response of rainbow trout (Oncorhynchus mykiss) growing from 50 to $170 \mathrm{~g}$ to supplements of either 1-arginine or 1threonine in a semipurified diet. J. Nutr. 125:970-975.

Rønnestad, I. and H. J. Fyhn. 1993. Metabolic aspects of free amino acids in developing marine fish eggs and larvae. Rev. Fish. Sci. 1:239-259.

Rønnestad, I., A. Thorsen and R. N. Finn. 1999. Fish larval nutrition: a review of recent advances in the roles of amino acids. Aquaculture 177:201-216.

Rønnestad, I., L. E. C. Conceicaõ, C. Aragaõ and M. T. Dinis. 2000. Free amino acids are absorbed faster and assimilated more efficiently than protein in postlarval Senegal sole (Solea senegalensis). J. Nutr. 130:2809-2812.

Rønnestad, I., S. K. Tonheim, H. J. Fyhn, C. R. Rojas-Garcia, Y. Kamisaka and W. Koven. 2003. The supply of amino acids during early feeding stages of marine fish larvae: a review of recent findings. Aquaculture 227:147-164.
Rust, M. B., R. W. Hardy and R. R. Stickney. 1993. A new method for force feeding larval fish. Aquaculture 116:341-352.

Santiago, C. B. and R. T. Lovell. 1988. Amino acid requirements for growth of Nile tilapia. J. Nutr. 118:1540-1546.

Susenbeth, A., T. Dickel, A. Diekenhorst and D. Hohler. 1999. The effect of energy intake, genotype, and body weight on protein retention in pigs when dietary lysine is the first-limiting factor. J. Anim. Sci. 77:2985-2989.

Tesser, M., B. F. Terjesen, Y. Zhang, M. C. Portella and K. Dabrowski. 2005. Free- and peptide-based dietary arginine supplementation for the South American fish pacu (Piaractus mesopotamicus). Aquac. Nutr. 11:443-453.

Verri, T., G. Kottra, A. Romano, N. Tiso, M. Peric, M. Maffia, M. Boll, F. Argenton, H. Daniel and C. Storelli. 2003. Molecular and functional characterisation of the zebrafish (Danio rerio) PEPT1-type peptide transporter. FEBS Lett. 549:115-122.

Wilson, R. P. 2003. Amino acid requirements of finfish and crustaceans. In: Amino Acids in Animal Nutrition (Ed. J. P. F. D`Mello). CAB International, Wallingford, Oxon, United Kingdom, pp. 427-447.

Zambonino Infante, J. L., C. L. Cahu and A. Peres. 1997. Partial substitution of di- and tripeptides for native proteins in sea bass diet improves Dicentrarchus labrax larval development. J. Nutr. 127:608-614.

Zhang, Y., K. Dabrowski, P. Hliwa and P. Gomulka. 2006. Indispensable amino acid concentrations decrease in tissues of stomachless fish, common carp in response to free amino acidor peptide-based diets. Amino Acids 31:165-172. 